\title{
Can the Pyrrhonian Sceptic Suspend Belief Regarding Scientific Definitions?
}

\section{Geometry and Scepticism Reconsidered}

\author{
Benjamin Wilck \\ Department of Philosophy, Humboldt-Universität, Berlin, Germany \\ benjamin.wilck@hu-berlin.de
}

\begin{abstract}
In this article, I tackle an heretofore unnoticed difficulty with the application of Pyrrhonian scepticism to scientific definitions. Sceptics can suspend belief regarding a dogmatic proposition only by setting up opposing arguments or considerations for and against that proposition. Since Sextus provides arguments exclusively against particular geometrical definitions in Adversus Mathematicos III, commentators have argued that Sextus' method is not scepticism, but negative dogmatism. However, commentators have overlooked the fact that arguments or considerations in favour of particular geometrical definitions were absent in ancient geometry, and hence unavailable to Sextus. While this might explain why they are also absent from Sextus' text, I survey and evaluate various strategies to supply arguments in support of particular geometrical definitions.
\end{abstract}

\section{Keywords}

Pyrrhonian scepticism - suspension of belief - Sextus Empiricus - Adversus Mathematicos I-VI - Definitions - ancient geometry - Euclid

\section{Introduction}

The Pyrrhonian Sceptic is someone who attempts to live a life without holding any beliefs. While commentators have debated whether the Sceptic is nonetheless able to hold beliefs of some kind, my paper shifts the focus to the question of whether there is any kind of belief about which the Sceptic cannot 
suspend belief. Specifically, I suggest that there is one kind of belief that seems to defy the sceptical method, namely scientific definitions.

In the Outlines of Scepticism $(=P H)$, Sextus Empiricus defines his sceptical method as an ability to suspend belief regarding any given dogmatic proposition by constructing pairs of equally convincing arguments, or considerations, in favour of and against that dogmatic proposition. In his six books of Against the Professors (Adversus Mathematicos, = M), though, Sextus nonetheless presents a series of straightforward refutations of particular scientific definitions, rather than oppositions of arguments. Consequently, commentators have argued that the method deployed in M I-VI is not Pyrrhonian scepticism, but is rather negative dogmatism.

There seems, however, to be a plausible solution to this difficulty: the apparent lapse from Pyrrhonian scepticism into negative dogmatism which we seem to find in $M$ I-VI can be rectified by simply supplying arguments in support of the particular definitions. Applied to geometrical definitions, which Sextus extensively attacks in M III, Against the Geometers, this strategy of supplying arguments in support of particular definitions accounts for geometrical theorems, which are usually accompanied by an argument (namely, a proof). Yet, it seems to fail in the case of geometrical definitions, for which the Geometers do not provide any proof or justification of some other sort. Sceptical inquiry requires opposing arguments, or considerations, both in favour of and against the given dogmatic proposition, whereas arguments or considerations in favour of particular definitions are notoriously absent in ancient Greek geometry. While this might explain why arguments in support of particular definitions are also absent in $M_{\text {III }}$, the present paper surveys and evaluates various nongeometrical, philosophical strategies to supplement such arguments.

In $M$ I-VI, Sextus launches an overall attack on six ancient mathēmata "arts and sciences, disciplines", which have later become known as the septem artes liberales: in $M$ I.41-320, on grammar; in II, on rhetoric; in III, on geometry; in IV, on arithmetic; in V, on astrology; and in VI, on music. Logic, however, is dealt with in $M$ VII-VIII (= Against the Logicians I-II). Sextus' opponents in $M \mathrm{I}-\mathrm{VI}$ are hoi dogmatikoi "the Dogmatists", more specifically, hoi apo tōn mathēmatōn "those [scil. people who put forward claims to knowledge or expertise; BW] in the arts and sciences" (M I.1). ${ }^{1}$ Sextus applies the same method

1 In Section 3.1 below, I lay out what Sextus means by "Dogmatist, dogmatic". 
in each of the six treatises of his Adversus Mathematicos. The attack focuses in each case on the first principles, but is also directed towards the theorems that are supposed to follow from these principles. The attack on the principles of a particular discipline concerns the conceivability or existence, as well as the definitions, of its elementary items. Sextus mentions throughout $M$ I-VI that if the principles of a particular discipline are demolished, then that entire discipline will be demolished altogether. ${ }^{2}$

\subsection{Sextus' Attack on Ancient Geometry}

Sextus' attack on the Geometers is directed primarily towards the first principles of geometry, especially towards putative definitions of elementary geometrical terms. $M$ III.22-107 set out a long chain of arguments against particular geometrical principles: in III.22-93, Sextus attacks various putative definitions of fundamental geometrical items (namely, the point in III.22-28, the line at III.29-76, the surface in III.77-82, and the body in III.83-91), while in III.94-107, his attacks address derivative geometrical items (namely, a straight line in III.94-99, the angle in III.100-106, and the circle in III.107). It is only in the last few sections of $M$ III (in III.108-116) that Sextus concerns himself with attacking geometrical theorems (or, to be exact, geometrical 'problems'), pertaining primarily to the cutting of lines and figures. ${ }^{3}$

Sextus calls his opponents in $M$ III hoi geōmetrai "the Geometers". It nonetheless remains uncertain who his opponents are in $M$ III, as Sextus never mentions any individual Geometer. The only exceptions are $M$ III.28, where Sextus names Eratosthenes as a Geometer, and III.57-58, where he refers to Aristotle as a defender of geometry. By contrast, Sextus expressly mentions the Epicureans as critics of geometry ( $M$ III.94-107; $M$ I.5, see section 3.3 below). Since variants of definitions that Sextus attacks in $M$ III are found in Euclid's Elements $(=E l$.$) , Heiberg (1888$, LXXII) takes Sextus to implicitly refer to Euclid. ${ }^{5}$ Recent commentators, however, have been more cautious about taking Euclid to be Sextus' target in $M$ III. While Mueller (1982, 69; 73-74) also regards Euclid's geometry as Sextus' target in M III, he notes differences between

2 See $M$ I.4O; 12O; III.18; 21; 82; 92-93; IV.1; V.49; VI.5.

3 For a detailed overview of the argumentative structure of $M$ III, see Freytag 1995, 17-18; Pellegrin et. al. 2002, 56-6o; Bett 2018, 33-34. For a philosophically oriented overview of $M$ III, see Mueller 1982, 72-76.

4 For references, see Dye \& Vitrac 2009, 168, n. 32.

5 In particular, Heiberg takes Sextus to cite Euclid's definitions of the line (El. I. def. 2) in $M$ iri.29 (see also III.37), of a straight line (El. I, def. 4) in III.94 (see also III.96), of the plane angle (El. I. def. 8) in III.10o, of the circle (El. I. def. 15) in III.107, as well as Euclid's problemproposition 'To bisect the given finite straight line' (El. I.1O) in III.109. 
Euclid's and Sextus' respective variants. On the basis of a rigorous philological comparison between the definitions common to Euclid and Sextus, Dye \& Vitrac (2009, 174-179) conclude that Euclid's definitions are neither Sextus' source nor his target in M III. Russo (1998, 212-213; cf. Dye \& Vitrac 2009, 169) suggests that Sextus' source in $M$ III.94-97 is (pseudo?)Hero's Definitiones (=Deff.), which records variants of two alternative definitions of a straight line cited in M III.94-99 (Deff. 4, Heiberg 1912, 16,21-18,5). Barnes (1988) argues that Sextus' attack on the six disciplines in $M$ I-VI does not address the specialized sciences, but rather their corresponding non-scientific arts: the artes liberales. On this view, $M$ III does not address scientific geometry as practised in Euclid's Elements, but instead the art of geometry. ${ }^{6}$ However, it is unclear what the difference between the art and the science of geometry amounts to. Moreover, the metamathematical terminology Sextus mentions in $M$ III strongly suggests that Sextus addresses a scientific discipline. ${ }^{7}$

\subsection{Sextus' Attack on the Definition of a Straight Line}

Each of the geometrical items attacked in $M$ III is subject to a complex and detailed treatment. For instance, Sextus attacks a straight line (eutheia) by five different arguments:

(i) In $M$ III.92-93, Sextus refers to arguments against the existence of the line in III.37-59, and argues that the non-existence of generic lines implies the non-existence of straight lines. ${ }^{8}$ In III.94, Sextus offers a more detailed argument against the existence of straight lines.

(ii) In III.95-97, by arguing that it is unintelligible or circular, Sextus targets a putative definition of a straight line as "the line which is placed equally with its parts" (grammē hè ex isou tois heautēs meresi keimenē, III.96, already mentioned in III.94) (henceforth abbreviated as "GHEITEMK").

(iii) In III.98, Sextus attacks a further putative definition of a straight line as "that [line] which rotates equally with its limits" (hêtis ex isou tois heautēs perasi strephetai) or as "that [line] which in rotating around its limits touches the plane with all its parts" (hêtis peri ta heautēs perata strephomenē pasi tois heautēs meresin haptetai tou epipedou), arguing that it is incompatible with physics.

6 Similarly, Corti (2015) argues that Sextus is not addressing scientific number theory in $M$ IV, but rather a non-scientific Pythagorean-Platonic theory of numbers.

7 Sextus speaks of geometry as proceeding from scientific definitions as deductive startingpoints to prove theorems: see Section 6.2 below. This suggests that Sextus' targets scientific geometry, rather than some non-scientific art of geometry.

8 See $P H$ I.8-10 in Section 3.1 below. 
(iv) In III.99, Sextus deploys the Mode from Reciprocity against a pair of circular definitions: that of a straight line as "that [line] which touches the plane with all its parts" (hêtis eis panta ta mere tou epipedou haptetai) and of the plane (epipedos) as "that which, when a straight line is drawn through it, touches [the plane] with all its parts" (di' hou hè katagomenē eutheia pasi tois meresin haptetai).

The putative definition of a straight line as GHEITEMK, which Sextus attacks in M III.95-97, appears to be a variant of Euclid's definition of a straight line in the Elements (El. I, def. 4): "a straight line is that [line] which lies equally with points on itself" (Eutheia grammè estin, hètis ex isou tois eph' heautēs sēmeiois keitai, Heiberg \& Menge 1883, 1,4-5). Yet, the version Sextus cites conceptually diverges from Euclid's definition in that it speaks of "parts" of the line, whereas Euclid speaks of "points". ${ }^{9}$ The variant listed in (Pseudo-?)Hero's Definitiones is closer to Euclid's: "a straight line is that [line] which lies equally with its own points on itself" (Eutheia [...] grammē estin, hètis ex isou tois ep' autēs sēmeiois keitai, Deff. 4, Heiberg 1912, 16,21-23). ${ }^{10}$ Earlier variants of that definition can be traced to Plato and Aristotle." ${ }^{11}$ The present paper focuses on Sextus' argument against the definition of a straight line as GHEITEMK in M III.95-97:

(95) And then, 'equal' ( $\tau o$ ' 'øov) is spoken of in two ways: in one way it is

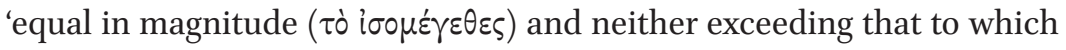
it is said to be equal nor being exceeded by it' - as when we say that a plank a cubit long is equal to what is a cubit long-while in another it

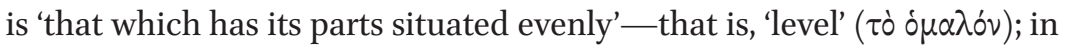
this way, at any rate, we call the floor 'equal' instead of 'level'. (96) Since, then, 'equal' is so called in two ways, when the Geometers in delineating

9 Cf. Mueller 1982, 72, n.5; Dye \& Vitrac 2009, 178-179; Bett 2018, 177, n. 57.

10 Russo $(1998,215)$ even speculates that $E l$. I, def. 4 is an editorial interpolation from Deff. 4.

11 Plato records the first extant definition of straight: "for, straight is that the middle of which is in front of both extremities" (euthu gar hou to meson amphoin toin eschatoin epiprothen hēi, Parmenides $\left.137 \mathrm{e}_{5}-6\right)$. Aristotle mentions a putative definition of a limited (i.e., finite) straight line (grammè peperasmenè eutheia) as "a limit of a plane that has limits, the middle of which is in front of the limits" (peras epipedou echontos perata, hou to meson epiprosthei tois perasin, Topics VI.11, 148b26-28). While the verb epiprosthein "to be in front of, to be before" is present in both Plato's version and the one Aristotle cites, it is absent from both Euclid's definition and the version Sextus cites in $M$ III.94 and 96. Still, that word reappears in the first definition of (pseudo-?)Euclid's Catoptrics: "a straight vision is that [line?] the middles of which are in front of all the extremes" (Opsin einai eutheian, hēs ta mesa panta tois akrois epiprosthei, Heiberg 1898, 312,17-312,18). I shall pick up the Catoptrics' definition in Section 6.3.5 below. 
the straight [line] say 'a straight line is the one that lies equally with its own parts', they are taking 'equally' either in the first signification or the second. But if it is in the first, they are completely senseless (¿vóntos); for that a straight line is equal in magnitude to its own parts and neither exceeding these nor being exceeded by these makes no sense. (97) But if it is in the second, they will be teaching by means of the very thing being investigated ( $\delta \imath^{\prime}$ aviov), if indeed they establish that it is straight from its having its parts lying in a level fashion and in a straight line, but something's lying in a straight [line] is not to be learned if we have not got a grip on the straight [line].

$M$ III.95-97, TRANS. BETT, MODIFIED

This argument against the putative definition of a straight line as GHEITEMK can be regarded as a representative example of the way in which Sextus attacks particular geometrical definitions in $M$ III. It can also be regarded as a representative example of the way Sextus attacks particular scientific definitions in $M$ I-VI.

The argument in $M$ III.95-97 seems to be a straightforward refutation of the Geometers' proffered definition of a straight line as GHEITEMK. Sextus' counter-argument against that definition amounts to the conclusion that GHEITEMK is not the definiens of a straight line. Consequently, it seems natural to reconstruct $M$ III.95-97 as displayed (henceforth R1):

(1) "Equal", which is contained in GHEITEMK, means "equal in magnitude" or "level". (premise)

(2) If "equal" means "equal in magnitude", then the putative definition of a straight line as GHEITEMK is senseless; and if "equal" means "level", then the putative definition of a straight line as GHEITEMK is circular. (premise)

(3) Therefore, the putative definition of a straight line as GHEITEMK is senseless or circular. (from 1, 2; implicit)

(4) If the putative definition of a straight line as GHEITEMK is senseless or circular, then a straight line is not defined as GHEITEMK. (premise; implicit)

(5) Therefore, a straight line is not defined as GHEITEMK. (from 3, 4)

This argument involves the construction of a classical dilemma. (2) sets out the following alternative: if the word "equal", which is mentioned in GHEITEMK, means "equal in magnitude", then this account is senseless and therefore not a definition; but if "equal" means "level", then this account is circular and therefore not a definition either. Since it is assumed in (1) that "equal" means "equal 
in magnitude" or "level", it follows that GHEITEMK does not define a straight line. (4) is to be supplied in order to make that inference deductively valid. On first glance, this reading seems to be the one best supported by Sextus' text. Moreover, it is a reading of Sextus' arguments against particular scientific definitions that we encounter frequently within the tradition of commentators on $M$ I-VI. As I am going to show in the next section, however, this reading does not conform with Sextus' own sceptical method. Thus, the present paper is not concerned with the question of the extent to which the argument in $M$ III.95-97 is effective in criticizing the given geometrical definition. ${ }^{12}$ Rather, the concern is with the question of precisely how such a criticism would be compatible with Pyrrhonian scepticism.

\section{Why are there No Oppositions of Arguments in Adversus Mathematicos III?}

The way in which Sextus presents his attack on the given definition of a straight line gives rise to a well-known difficulty according to which $M$ III appears not to be a work of Pyrrhonian scepticism, but rather of negative dogmatism. Against this, I shall propose alternative ways of interpreting the argument in $M$ III.95- $97^{13}$

\subsection{Sextus' Definition of Pyrrhonian Scepticism}

The initial reconstruction of the argument in $M$ III.95-97 remains close to Sextus' text. Yet, it has a noticeable disadvantage: the argument is conducted in a purely negative, destructive manner, which does not square with Sextus' own method of Pyrrhonian scepticism. The Sceptic does not simply demolish his opponents' views. Instead, the Sceptic sets up oppositions of equally convincing arguments for conflicting conclusions so as to induce a suspension of belief, as defined in Sextus' major work, the Outlines of Scepticism:

12 The criticisms put forward in $M$ III.95-97 have also been restated by contemporary commentators, philosophers, and mathematicians, and independently of Sextus. For instance, Golos $(1968,8-9)$ applies the same objection from circularity that we find in $M$ III.97 to Euclid's definition of a straight line (El. I. def. 4.): "It is circular and should be avoided. It is impossible to define 'lies evenly' without using the concept of 'straight' or something synonymous with it. [...] In modern systems the problem of circularity [...] is avoided by taking many words as undefined [...]." Moreover, Heath $(1956$, i, 167) and Eves $\left(195^{8}, 35\right)$ also reproach the obscurity and unintelligibility of $E l$. I. def. 4.

13 While my discussion focuses on $M_{\text {III }}$, the same difficulty can be attested for all the arguments against particular putative scientific definitions in $M_{\mathrm{I}} \mathrm{-VI}$, as well as in $M$ VII-XI and parts of $P H$. 


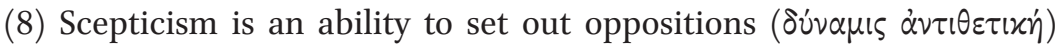
among things which appear and are thought of in any way at all, an abil-

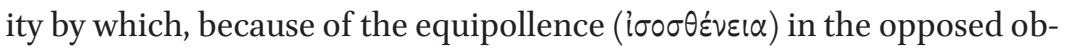
jects $(\pi p \alpha \hat{\gamma} \mu \alpha)$ and accounts $(\lambda \hat{o} \gamma \circ \varsigma)$, we come first to suspension of belief ( $\dot{\pi} \pi \circ \chi \dot{\eta})$ and afterwards to tranquility ( $\dot{\tau} \tau \alpha \rho \alpha \xi i \alpha)$. (9) We call it an ability not in the fancy sense, but simply in the sense of "to be able to". Things which appear ( $\varphi$ aाvó $\mu \varepsilon v \alpha)$ we take in the present context to be objects of perception, which is why we contrast them with objects of thought. "In any way at all" can be taken either with "an ability" (to show that we are to understand the word "ability" in its straightforward sense, as we said), or else with "to set out oppositions among things which appear and are thought of": we say 'in any way at all' because we set up oppositions in a variety of ways-opposing what appears ( $\varphi \alpha$ lvó $\mu \varepsilon v \alpha)$ to what appears,

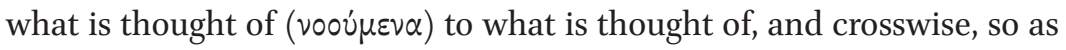
to include all the oppositions. Or else we take the phrase with "the things which appear and are thought of", to show that we are not to investigate how what appears appears or how what is thought of is thought of, but are simply to take them for granted. (10) By "opposed accounts" we do not necessarily have in mind affirmation and negation, but take the phrase simply in the sense of "conflicting accounts". By "equipollence" we mean equality with regard to being convincing or unconvincing: none of the conflicting accounts takes precedence over any other as being more convincing. Suspension of belief is a standstill of the intellect, owing to which we neither reject nor posit anything. Tranquility is freedom from disturbance or calmness of soul. We shall suggest in the chapter on the aim of scepticism how tranquility accompanies suspension of belief.

PH I.8-10, TRANS. ANNAS \& BARNES, SLIGHTLY MODIFIED, MY EMPHASIS

In this passage, Sextus succinctly defines the sceptical mode of inquiry by four features:

(i) "ability": Pyrrhonian scepticism is an ability in the sense that it is not a body of knowledge or set of beliefs, but rather a skill or topic-neutral method. Specifically, Pyrrhonian scepticism is an ability to set up oppositions (dunamis antithetikē).

(ii) "equipollence": Scepticism consists in the balancing of opposing arguments. ${ }^{14}$ Arguments are opposed to one another if their conclusions are

14 See $P H$ I.12 (in Annas' \& Barnes' translation): “[...] The chief constitutive principle of scepticism is the claim that to every account ( $\lambda$ y $^{\circ} \varsigma$ ) an equal account is opposed; for it is from this, we think, that we come to hold no beliefs." See also $P H$ I.18; I.2O2-2O5. 
incompatible with one another. Yet, a sceptical counter-argument must not only amount to a rival conclusion; it must also be as convincing as the argument given in support of the given dogmatic belief. Sextus qualifies the Sceptic's opposition of arguments as one occurring between conflicting appearances (phainomena) or between conflicting thoughts (nooumena) or between conflicting appearances and thoughts.

(iii) "suspension": The balancing of opposing arguments is supposed to bring about a suspension of belief such that the Sceptic is unable to prefer the given argument to its counter-argument, and vice versa.

(iv) "tranquility": Suspension of belief is in turn supposed to bring about an intellectual tranquility in the Sceptic, in line with the ultimate goal of Pyrrhonian scepticism: a cure from the rashness of dogmatic aspirations to knowledge and expertise.

Pyrrhonian scepticism is thus an ability to find for any given dogmatic argument an equally convincing counter-argument. It is controversial whether the last feature, tranquility, is a constituent part of Sextus' definition of Pyrrhonian scepticism, or whether it is a presumption or consequence of that definition. ${ }^{15}$ In any case, Sextus states that equipollence of opposed arguments leads to a suspension of belief and tranquility, rather than to confusion or anxiety. In the present paper, I disregard the tranquility feature, and focus solely on the first three of the four aforementioned characteristics of Pyrrhonian scepticism. I also disregard the philosophical intricacies concerning Sextus' characterization of the relation between equipollence and suspension of belief, and simply assume that suspension of belief is somehow brought about by equipollence. ${ }^{16}$ Sextus' term for "argument" is logos, which can be broadly understood as "account, consideration". While the Sceptic must not himself assent to any dogmatic beliefs, the Sceptic may appeal to any argument, or consideration, in favour of a given dogmatic claim to construct an opposition that leads to a suspension of belief regarding whether or not that dogmatic claim is true.

The method of Pyrrhonian scepticism is opposed not only to dogmatic philosophy, but also to Academic Scepticism, which is a negative kind of dogmatism. Sextus prefaces his definition of Pyrrhonian scepticism by a threefold classification of the modes of philosophical inquiry:

15 For the view that intellectual tranquility is not an essential property of Pyrrhonian scepticism, cf. Machuca 2006.

16 For a discussion of the scholarly debate on whether the relation between equipollence and suspension of belief is a 'causal' or 'psychological' one, or whether it is a 'rational' or 'normative' one, see Perin 2010, ch. 2. 
(3) Those who are called "Dogmatists" in the proper sense of the word think that they have discovered the truth-for example, the schools of Aristotle and Epicurus and the Stoics, and some others. The schools of Clitomachus and Carneades, and other Academics, have asserted that things cannot be apprehended. And the Sceptics are inquiring. (4) Hence the most fundamental kinds of philosophy are reasonably thought to be three: the Dogmatic, the Academic, and the Sceptical. [...].

$P H$ I.3-4, TRANS. ANNAS \& BARNES, SLIGHTLY MODIFIED

Positive dogmatism and negative dogmatism alike are excluded by Pyrrhonian scepticism. While any kind of dogmatic inquiry presents itself as final, Pyrrhonian scepticism is non-dogmatic insofar as its mode of inquiry does not terminate in any doctrine. Sextus points out that skeptikos "Sceptic, sceptical" means "one who inquires" (from skeptesthai "to inquire", $P H$ I.7). The perpetual nature of the Pyrrhonian Sceptic's inquiry implies that a Pyrrhonian Sceptic is not committed to any beliefs; instead, he is able to find for every given argument an equally convincing counter-argument, which brings about a suspension of belief.

While this defines the Sceptic, one might wonder precisely how Sextus defines the Dogmatist. Pyrrhonian scepticism consists in constructing oppositions of dogmatic arguments, which is supposed to be opposed to Dogmatism. In $P H$ I.3, Sextus already provides a characterization of the Dogmatist, according to which holding the belief that one has discovered the truth is called "dogmatic". Such an attitude is typically found among members of a philosophical or scientific school, whereas Pyrrhonian scepticism does not belong to any school (see $P H$ I.16). Sextus defines dogmatikos "Dogmatist, dogmatic" as follows:

(13) When we say that Sceptics do not hold beliefs ( $\mu \dot{\eta} \delta \circ \gamma \mu \alpha \tau i \zeta \varepsilon v)$, we do not take "belief" $(\delta \dot{\gamma} \gamma \mu \alpha)$ in the sense in which some say, quite generally, that belief is acquiescing in something; for Sceptics assent to the feelings $(\pi \dot{\alpha} \theta 0 \varsigma)$ forced upon them by appearances $\left(\varphi \alpha \nu \tau \alpha \sigma^{\prime} \alpha\right)$ - for example, they would not say, when heated or chilled, "I think I am not heated (or: chilled)". Rather, we say that they do not hold beliefs in the sense in which

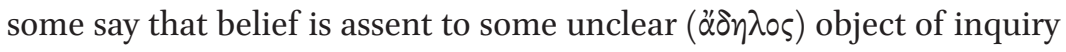
in the sciences; for Pyrrhonists do not assent to anything unclear. 
Annas \& Barnes (2000) translate dogma as "belief", which is justified in light of the fact that the Greek word dogma is originally used in the sense of "belief".17 Sextus here defines "dogmatic" as an assent to something unclear, non-evident, that is to say, something that is not given in appearance. He qualifies this definition by saying that the Sceptic does not assent to any non-evident object of inquiry in the sciences. One way to understand this is that the Sceptic does not assent to any scientific beliefs. ${ }^{18}$ If a belief were dogmatic just in case it is a scientific belief, though, then non-scientific beliefs about how things really are would not count as dogmatic. However, Sextus is likely to consider as dogmatic also non-scientific beliefs about how things really are, as long as they involve an assent to something non-evident, not given in appearance.

\subsection{The First Difficulty: Negative dogmatism in Adversus Mathematicos III}

According to the reconstruction in R1, the argument in $M$ III.95-97 does not satisfy the second requirement for Pyrrhonian scepticism, as it does not establish an equilibrium of opposing arguments, and in fact does not even establish an opposition of arguments at all. What is more, not only does the reconstruction in R1 not square with Sextus' own definition of scepticism, but it even makes Sextus' argument in $M$ III.95-97 appear to be the contrary opposite of scepticism, namely dogmatism. The argument appears to be a straightforward refutation of the Dogmatist's proffered definition of a straight line: (2) and (4) are dogmatic assertions, just as the conclusion, which asserts that GHEITEMK does not define a straight line. The fact that the conclusion is a negative assertion, which opposes the given dogmatic definition, does not make the argument any less dogmatic; rather, it makes it an instance of negative dogmatism. The argument in $M$ III.95-97 seems to have Sextus endorse the negative conclusion that GHEITEMK does not define a straight line. Therefore, the result of the reconstruction in $\mathrm{R} 1$ is not a suspension of belief regarding the question of whether or not a straight line is defined as GHEITEMK, but instead yet another dogmatic belief.

This is typical of all arguments against particular putative scientific definitions in $M$ III, and in $M$ I-VI in general, and has led commentators to think

17 See, e.g., Plato, Republic VII, 538c6 and Theaetetus 158d3; cf. Burnyeat 1980, 26.

18 This line of interpretation is defended by Barnes $(1997,73-75)$. Frede $(1997,18-19)$ takes dogmatic beliefs to be also those that are believed as a result of deriving them from scientific or philosophical beliefs. For an overview of the debate, see Perin 2010, 150-161; Morison 2019, section 3.4. 
that the method of philosophical inquiry deployed in $M \mathrm{I}-\mathrm{VI}$ is not Pyrrhonian scepticism, but is rather negative dogmatism. ${ }^{19}$ This view finds its most characteristic expression in Janáček $(1972,87)$, who takes the entire $M$ I-VI to be Sextus' late renunciation of his own sceptical method: "One fact is quite clear from the first moment: this is the non-sceptical character of $M$ I-VI [...]." Janáček supports this interpretation by pointing out that words like anairesis (destruction) and antirrēsis (refutation, counter-argument) occur much more frequently in $M \mathrm{I}-\mathrm{VI}$ than in $P H$ and $M \mathrm{VII}-\mathrm{XI}$, while the language of epoche $\bar{e}$ (suspension) has disappeared almost entirely from $M$ I-VI.

Sextus himself seems to expressly assert that he is demolishing the Geometers' claims in $M$ III, as in the passage immediately preceding $M$ III.95-97:

[92] In this way, then, it turns out that the principles of geometry are groundless ( $\dot{\alpha} v 0 \pi \delta \sigma \tau \alpha \tau \circ \varsigma)$; but if these are done away with, no other geometrical theory can be assembled either. For whatever this may be

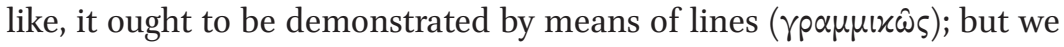
have shown that the generic line is nothing, from which it follows that none of the specific ones exist either, whether one supposes this to be straight or bent or in any other condition. [93] Hence it would perhaps

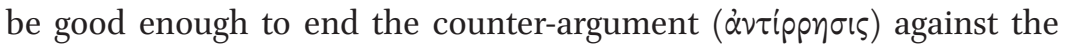
Geometers here; nonetheless, we will continue the contest and try to teach $(\delta 1 \delta \dot{\alpha} \sigma \chi \varepsilon v)$ that even if we leave alone the principles of geometry, the Geometers cannot assemble or demonstrate a theorem.

$M$ III.92-93, TRANS. BETT, MODIFIED

Thus, the reconstruction in Ri captures Sextus' style of writing in $M$ I-VI, and it conforms with the tradition of commentators. The fact that Sextus fails to construct opposing arguments in $M$ III, however, does not comply with the

19 See, e.g., Pappenheim 1877, 17-18; Zeller 1881, 40, n. 2; Apelt 1891, 258-259; Janáček 1972; Janáček 1994; Russo 1972, viii, n. 2; Pellegrin et. al. 2002, 23-24; cf. Barnes 1988, 76-77; Desbordes 1990, 168-170. For an overview of the scholarly debate on negative dogmatism in $M$ I-VI, see Blank 1998, l-lv; Bett 2018, 11-15; Morison 2019, section 5; cf. ibid., section 4.2. Many commentators even take Sextus to argue in $M \mathrm{I}-\mathrm{VI}$ not only from a dogmatic, but from an empiricist viewpoint: see, e.g., Dumont 1972, 164; Mueller 1982; Freytag 1995. Admittedly, though, Mueller $(1982,70)$ concedes that Sextus need not himself be committed to the arguments in $M$ III: "Sextus, too, relies on empiricist ideas, but, as a sceptic, he can use the ideas of others without committing himself to them." 
sceptical method we find in other of Sextus' works. This gives rise to the following difficulty:

(1) Pyrrhonian scepticism regarding particular geometrical definitions requires arguments or considerations both in favour of and against such definitions.

(2) Sextus' arguments against particular geometrical definitions in $M$ III do not state any arguments or considerations in favour of such definitions.

(3) Therefore, Sextus' arguments against particular geometrical definitions in M III are not instances of Pyrrhonian scepticism (but rather of negative dogmatism).

While (1) lays down the construction of opposing arguments in support of conflicting beliefs as the basic requirement of sceptical inquiry, (2) describes Sextus' actual approach in $M$ III. (1) and (2) imply that $M$ III is not a work of Pyrrhonian scepticism, but of negative dogmatism. This is the first, wellknown difficulty with the application of Pyrrhonian scepticism to particular scientific definitions; it has earned Sextus the reputation of being a Dogmatist in $M$ III, and in $M$ I-VI in general.

\subsection{A Potential Solution to the First Difficulty: Elliptic style in M III?}

We should refrain from the view that $M$ I-VI is an involuntary slip into negative dogmatism, given that Sextus shows himself aware of the fact that the counterargument by which the Sceptic opposes the Dogmatist's proffered argument is as dogmatic as the Dogmatist's argument itself. Recall, for example, that Sextus says in $P H$ I.1O (see Section 3.1 above) that "suspension of belief is a standstill of the intellect, owing to which we neither reject nor posit anything", which implies that the denial of a given proposition is as dogmatic as its affirmation. Moreover, in $P H$ I.2O3, Sextus expressly calls the sceptical counter-argument "dogmatic". Already in PH I.3 (see Section 3.1 above), Sextus also calls "dogmatic" the doctrine that the truth cannot be apprehended about anything, which he ascribes to Academic Sceptics such as Clitomachus and Carneades. Furthermore, when Sextus attacks the criterion of truth in $\mathrm{PH}$ II.79, he concedes that arguing for the non-existence of the criterion of truth would be a dogmatic, non-sceptical move. Therefore, Sextus takes negative dogmatism to be as dogmatic as positive dogmatism. It is therefore unlikely that Sextus would have lost sight of the dogmatic character of $M \mathrm{I}-\mathrm{VI}$.

In addition, Sextus' programmatic remarks at the beginning of $M I$ indicate that he by no means intends to conduct straightforward refutations leading to 
a dogmatic denial of scientific doctrines, but rather that he intends to apply his sceptical method also to the arts and sciences: ${ }^{20}$

[5] Well, this is more or less where Epicurus was coming from, to hazard a guess, when he saw fit to make war on the disciplines. But the Pyrrhonists did so not because they contribute nothing to wisdom - for that is a dogmatic statement - nor because of being characterized by lack of education; for besides being educated and having wider experience than the other philosophers, they are also indifferent to the opinion of the mob. [6] Not that this is due to hostility towards anyone (a vice of that sort is far from their gentleness); but the same sort of thing happened to them in the case of the disciplines as it did in the case of philosophy as a whole. For just as they went after it with a longing to attain the truth, but after encountering conflict of equal strength and lack of uniformity in the objects they suspended judgement, so too in the case of the disciplines they set out to pick them up, here too seeking to learn the truth, but on discovering equal impasses they did not conceal them. [7] For this reason we too will pursue the same method as them and will try without contentiousness to select and set out the effective things said against them.

$M$ I.5-7, TRANS. BETT

This passage suggests that in $M \mathrm{I}-\mathrm{VI}$, Sextus appeals to Epicurean arguments against the arts and sciences, not in order to reject scientific doctrines, but in order to produce an equilibrium of arguments offered by the arts and sciences on the one hand and corresponding counter-arguments offered by Epicurean philosophers on the other. As a matter of fact, most of the arguments Sextus uses as counter-arguments in $M$ III are simply cited from Epicurean sources. ${ }^{21}$ In his attack on the second putative definition of a straight line in III.98, Sextus even expressly refers to the Epicureans. Thus, Sextus attack on geometrical

20 For a discussion of $M$ I.5-7, cf. Blank 1998, 70-85; Decleva Caizzi 1992, 318; 293-296; Hankinson 1995, 226-227; cf. Spinelli 2010, 254-256. As a consequence of his interpretation of $M$ I-VI as negative dogmatism, Janáček $\left(1972,13^{2-133)}\right.$ takes $M$ I.5-7 to be alien material: "The introduction M I 1-40, which I have always considered as extraneous matter in M I-VI, might perhaps indicate that the original intention was sceptical." Yet, before excising anything from Sextus' text, we should try our best to reconstruct Sextus' arguments in $M \mathrm{I}-\mathrm{VI}$ in sceptical fashion.

21 See Apelt 1891, 256-258; Mueller 1982; Delattre 1994, 101-104; Cambiano 2008, 587-590; Bénatouil 2010; Spinelli 2010, 251-258. See $M$ I.1 (in Bett's translation): "The counterargument against those in the disciplines seems to have been wielded quite generally by both the Epicureans and the Pyrrhonists, though their attitudes were not the same. [...]". In $M$ I.2-3, Sextus offers an anecdote about Epicurus' motives for turning against the arts and sciences. 
doctrines in $M$ III is not aimed at rejecting these doctrines, but at producing rival arguments so as to induce a suspension of belief. Therefore, the negative, refutational arguments in $M$ I-VI should not be taken at face value; instead of displaying Sextus' epistemic commitments, they should be regarded as a mere source material for Sextus to perform his sceptical attacks. ${ }^{22}$

In order to resolve the first difficulty (stated in Section 3.2. above) and to evade the interpretation of negative dogmatism, an interpretation is required that shows how to reconstruct Sextus' argument in M III.95-97 as an instance of Pyrrhonian scepticism. One may suggest that the lack of arguments in support of particular definitions can plausibly be explained by elliptic style. The charge of a lapse from Pyrrhonian scepticism into negative dogmatism, which seems to be justified by what we find in $M$ I-VI, could be fended off by way of supplementing positive arguments opposing Sextus' refutational arguments. ${ }^{23}$

According to this strategy, it is possible to read Sextus as indeed constructing equal and opposing arguments in $M \mathrm{I}-\mathrm{VI}$, on the condition that we take those arguments to provide only the negative counter-arguments without also explicitly providing the positive arguments. Viewed from this perspective, Sextus' negative arguments in $M$ I-VI emerge as only one arm of sceptical reasoning, namely as the negative counterparts to the given dogmatic accounts from which the Sceptic's reasoning proceeds - and not themselves as dogmatic positions.

\section{The Sceptical Mode of Inquiry}

The solution to the difficulty about negative dogmatism simply seems to consist in incorporating additional dogmatic material into the refutational arguments against particular definitions, which Sextus presents in $M$ I-VI, such as the argument against the definitions of a straight line as GHEITEMK. But how precisely is the supplementation of the missing argument in $M$ III.95-97 supposed to work? In order to understand how the missing positive argument is to be inserted into the supposedly elliptic structure of the sceptical opposition of arguments, we first need to have a more precise understanding of the structure of the Sceptics' opposition.

\footnotetext{
22 Cf. $P H$ I.14, where Sextus says that the Sceptic, when he denies proposition $p$ by using the Dogmatist's argument against $p$, does not mean the same thing as the Dogmatist.

23 The view that positive arguments in support of particular definitions are implicit in $\mathrm{M} \mathrm{I}_{\mathrm{I}}$ VI appears to be presumed in Barnes 1988, 72-77; Blank 1998, l-lv; Morison 2019, sections 4.2 and 5 .
} 


\subsection{The Standard Interpretation of Pyrrhonian Scepticism}

Annas \& Barnes $(1985,25)$ offer the standard interpretation of the structure of the Sceptic's opposition: ${ }^{24}$

(1) (Positive argument)

Object $a$ appears to have property $F^{+}$in situation $\mathrm{S}^{+}$

$S^{+}$

$$
\therefore F^{+} a
$$

(2) (Negative counter-argument)

Object $a$ appears to have property $F^{-}$in situation $S^{-}$

$S^{-}$

$$
\therefore F^{-} a
$$

(3) (Equipollence)

We can neither prefer (1) to (2) nor (2) to (1)

(4) (Suspension)

Therefore, we can neither affirm nor deny whether a is $F^{+}$or $F^{-}$(from $1,2,3)$

The word "situation" is meant to indicate any kind of argument, or consideration, in favour of the Dogmatist's proffered proposition. While (1) introduces a positive consideration in support of the Dogmatist's proposition, (2) states the corresponding counter-argument leading to a rival, conflicting conclusion. The equipollence of (1) and (2) is introduced as an additional premise, (3), and the entire argument concludes with a suspension of belief. The standard interpretation of the Sceptic's opposition prescribes a general way to reconstruct Sextus' argument in sceptical fashion. By instantiating the variables of this

24 See also Annas \& Barnes 1985, 24; 39; 82-83; 98; 102; 121-122. The standard view was anticipated by Striker $(1983,100)$, and adopted by many others such as Hankinson $(1995,159)$. While I follow Morison (2011, 287-289; 2018, 287-293; 2019, section 3.5.1) in ascribing the standard view to the aforementioned commentators, one might also contest-as does Bett (2019, 110-111) — whether it is entirely fair to attribute this view to these commentators. (An interpretation that expressly endorses the standard view can be found in Perin $(2010,40)$. Perin argues that it is in accordance with an epistemic commitment to the rational norm that one should or must suspend belief when confronting equally convincing opposed arguments.) Moreover, while Annas' \& Barnes' schema appears to be designed to capture Sextus' description of the Ten Modes of Aenesidemus, I follow Morison also in taking all the sets of sceptical Modes, including the Five Modes of Agrippa, to reflect the structure of the Sceptic's opposition. It should be noted, however, that the Sceptic's opposition does not depend on any of the Modes. 
schema by the concrete terms from $M$ III.95-97, we gain a second interpretation of Sextus' argument against the definition of a straight line as GHEITEMK (henceforth R2):

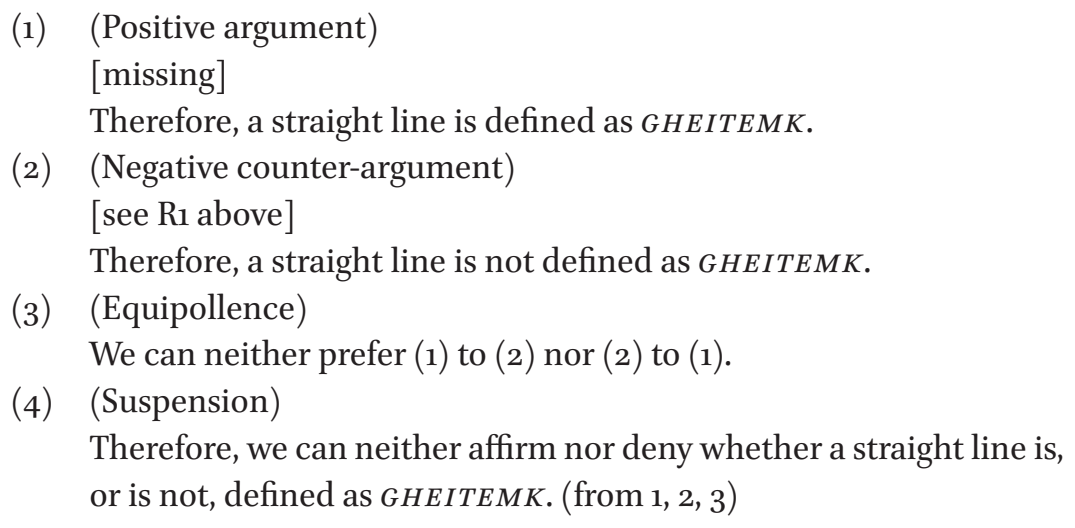

While the reconstruction in Ri takes the argument in M III.95-97 to be one single argument and a straightforward refutation of the given definition, R2 takes that refutational argument to be but a premise of the entire sceptical argument. Accordingly, it takes the argument in support of the proffered definition of a straight line to be a second premise. By taking suspension of belief regarding that definition as the conclusion of the entire argument, the reconstruction in $\mathrm{R}_{2}$ avoids the major disadvantage of the interpretation in R1, which is that the argument in M III.95-97 amounts to a dogmatic conclusion instead of to a suspension of belief.

\subsection{The New Interpretation of Pyrrhonian Scepticism}

Morison (2011, 289; 2018, 288-289; 2019, section 3.5.1) has recently criticized Annas' and Barnes' schema of sceptical reasoning for two reasons. Firstly, Morison argues that premise (3) - which states the equipollence of the opposing arguments-is a dogmatic assertion itself, whereas the Sceptic's reasoning must not assent to any dogmatic beliefs. Secondly, Morison reproaches the standard view for its suggestion that the Sceptic's suspension of belief is a logical conclusion. ${ }^{25}$ Subsequently, Morison puts forward an interpretation of the structure of the Sceptic's opposition that avoids these two disadvantages of the standard view:

25 Sextus remarks in $P H$ I.7 that suspension of belief is "an affection (pathos) that comes about (gignetai) in the Sceptic after the investigation", or, as Barnes $(1997,59)$ himself puts it elsewhere: "The onset of ह̇ $\pi \circ \chi \eta$ is something which simply happens to us". 
(Positive argument)

Object $a$ appears to have property $F^{+}$ in situation $S^{+}$:

$S^{+}$

$\therefore F^{+} a$
(Negative counter-argument)

Object $a$ appears to have property $F^{-}$ in situation $S^{-}$:
$S^{-}$

$\therefore F^{-} a$

(Suspension of belief)

We can neither affirm nor deny whether $a$ is $F^{+}$or $F^{-}$.

Morison's alternative interpretation opposes the two rival arguments without making them the premises of any argument; moreover, it does not present the suspension of belief as a logical conclusion or as the consequence of accepting the conclusion of an oppositional argument. Instead, a suspension of belief occurs once the Sceptic is confronted with the rival arguments. By instantiating Morison's schema with the concrete terms from $M$ III.95-97, we gain a third reconstruction of Sextus' argument against the definition of a straight line as GHEITEMK (henceforth $\mathrm{R}_{3}$ ):

(Positive argument)
$[$ missing]

Therefore, a straight line is defined as GHEITEMK.
(Negative counter-argument) [see $\mathrm{R} 1$ above]

Therefore, a straight line is not defined as GHEITEMK.

\section{(Suspension of belief)}

We can neither affirm nor deny whether a straight line is, or is not, defined as GHEITEMK.

Like $\mathrm{R}_{2}$, the interpretation in $\mathrm{R}_{3}$ does not take the argument in $M$ III.95-97 to be a straightforward refutation and it also has Sextus' argument amount to a suspension of belief. In contrast to $\mathrm{R}_{2}$, however, $\mathrm{R}_{3}$ does not take the Sceptic's suspension of belief to be a part of any argument. Rather, once the Sceptic gets himself in the right epistemic condition of facing equally convincing and opposing evidence regarding the question of whether or not GHEITEMK defines a straight line, a suspension of belief on that matter will be brought about immediately. 
Having gained an insight into the structure of the Sceptic's opposition, we should now be able to supply the arguments in support of particular definitions that are missing from $M$ III if we take these arguments to be implicitly stated in Sextus' text, as proposed in Section 3.3 above. If the solution to the problem of negative dogmatism in $M$ III consists in supplying the positive dogmatic material that Sextus supposedly omits, then it will be required to find an argument in support of the given definition of a straight line as GHEITEMK that is as convincing as the counter-argument set out in M III.95-97 (see R1 above). What positive argument might Sextus have in mind ? Is there any argument that amounts to the conclusion that GHEITEMK defines a straight line and that is as convincing as the corresponding counter-argument? Can there be any such argument at all? In what follows, I argue that another, more radical difficulty arises when we try to fill the gap in Sextus' text.

\subsection{The Second Difficulty: Definitions in Ancient Geometry}

It appears that there cannot be any argument in support of the definition of a straight line as GHEITEMK; for, as a matter of fact, definitions are not argued for in ancient Greek geometry. In ancient geometry, definitions are not accompanied by any proof or other sort of justification. This is in line with the practice of ancient science, in which definitions are always stated without any justification in their favour. ${ }^{26}$ The absence of arguments in support of particular definitions can equally be observed in the other ancient Greek sciences such as astronomy and medicine. Geometers such as Euclid, Archimedes, and Apollonius appeal to definitions as starting-points of their respective proofs in order to justify geometrical theorems. However, none of these Geometers states any sort of justification in support of these definitions. It should be noted that justifying a particular scientific definition does not mean to show

26 Aristotle's scientific writings, however, can be regarded to be an exception to this rule: in his Physics and de Anima, for instance, Aristotle himself dialectically examines and establishes definitions of basic scientific notions. On dialectical establishing of a particular definition, see Section 6.3.4 below. Moreover, there are 17 definitions that seem to be stated as conclusions of ancient geometrical proofs: Euclid's 'definitions' of a medial straight line (El. X.21) and of the twelve subspecies of an irrational line (El. X.36-41; 73-78), as well as Apollonius' 'definitions' of parabola, hyperbola, ellipsis, and opposite conic sections (Conics I.11-14). However, one might wonder whether these propositions are definitions at all. 
that the given definition expresses a true statement, but rather to show that it is indeed a definition.

As we know from the remarks about contemporary mathematics in Plato's Republic, ${ }^{27}$ Geometers 'hypothesize', that is to say, assume their definitions without proof. That Sextus is aware of this scientific practice is clear from $M$ III.7-17, where he presents arguments against the Geometers' practice of proving theorems from unproved principles, especially definitions. ${ }^{28}$

In addition, the view that definitions cannot be proved was famously argued for by Aristotle. Since a definition is a first principle of proof, it serves to prove scientific theorems, but cannot itself be proved; otherwise either an infinite regress of proofs or a circular proof would occur. ${ }^{29}$ Moreover, every scientific proof must be performed within the boundaries of its appropriate subjectmatter, whereas an inquiry into the reasons for the principles would extend beyond that subject-matter. ${ }^{30}$

Of course, the Sceptic can neither assert that the Geometer must, nor that he must not, argue in favour of his own definitions, as these would be dogmatic positions. Yet, the Sceptic is nonetheless confronted with the sheer fact that the Geometer does not argue for his definitions. The Sceptic will therefore not be provided with any argument to which he could appeal in support of a particular geometrical definition.

Accordingly, the account targeted in $M$ III.95-97 only consists of a dogmatic claim, namely the definition of a straight line as GHEITEMK, without any corresponding argument in its favour. This is indeed a difficulty for the Sceptic, as sceptical inquiry requires there to be arguments or considerations on both sides of the opposition. When the dogmatic claim is a definition, the Sceptic is expected to invoke evidence not only against, but also in favour of that definition.

While the lack of a positive consideration in Sextus' arguments against particular geometrical theorems (in $M$ III.108-116) can be compensated for by supplying suitable proofs or constructions, this cannot be done for scientific principles such as geometrical definitions. Consequently, the strategy of supplementing additional dogmatic material in order to evade negative dogmatism in $M$ III appears not to be successful if the given dogmatic proposition is a geometrical definition. The absence of arguments in support of particular

\footnotetext{
27 See Plato, Republic VI, 510c2-d4.

28 Cf. the parallel passages in $M$ VII.367-378; see Section 6.2 below.

29 Topics I.1, 100a3o-b21; VIII.3, 158b5-8; Posterior Analytics I.2, 72a15-24; I.3; I.12, 10oa3ob21; I.19-22; II.3-6.

$30 \quad$ Analytica Posteriora I.7; I.9, 76a16-25; cf. Physics I.2, 184b27.
} 
geometrical definitions from ancient geometry might even explain the absence of such arguments in $M$ III.

As a result, Sextus seems not only to fail to apply Pyrrhonian scepticism to particular geometrical definitions in $M$ III, but beyond that, a suspension of belief regarding particular definitions seems not even possible at all. The confrontation of Pyrrhonian scepticism with ancient geometry gives rise to a second difficulty:

(1) Pyrrhonian scepticism regarding particular geometrical definitions requires arguments or considerations both in favour of and against such definitions.

(2) The definitions stated in ancient geometry are not accompanied by any arguments or considerations in their favour.

(3) Therefore, Sextus' arguments against particular geometrical definitions in $M$ III cannot be instances of Pyrrhonian scepticism.

(1) represents the sceptical mode of inquiry, while (2) is entailed by the geometrical mode of inquiry. (1) and (2) together imply that there are no arguments or considerations in favour of a particular geometrical definition to which the Sceptic could appeal, in which case sceptical inquiry into a given geometrical definition cannot proceed. This implies (3), the conclusion that the Sceptic is unable to suspend belief regarding particular geometrical definitions.

\subsection{The Relation Between the Two Difficulties}

The second difficulty (stated in the previous section) is a more radical version of the first one (stated in Section 3.2 above). According to the first difficulty, Sextus' attacks on particular geometrical definitions in $M$ III are not instances of Pyrrhonian scepticism because they fail to state arguments in support of such definitions and thus to set up oppositions of arguments. Elliptic style can explain the absence of opposing arguments in $M$ III only if we are able to find argumentative support for the particular geometrical definitions which Sextus attacks in $M$ III. According to the second difficulty, however, this strategy does not succeed because there appear to be no arguments in support of such definitions that the Sceptic could appeal to, in which case Pyrrhonian scepticism is not applicable to particular geometrical definitions at all.

Sextus is able to rely upon an entire tradition of destructive arguments against particular geometrical definitions, especially those provided by the Epicureans. Yet, Sextus does not rely in the same way upon arguments in support of particular geometrical definitions. While commentators have noted that Sextus does not offer any arguments in support of the definitions he 
attacks in $M$ III, it has remained unnoticed that such arguments were not available to Sextus from ancient geometrical treatises. The second difficulty suggests that the threat of negative dogmatism in interpreting $M_{\text {III }}$ is far more serious than has been thought to date.

Since the supposedly missing arguments in support of particular geometrical definitions can be supplemented only if such arguments are available to the Sceptic at all, the solution to the first difficulty presupposes that of the second difficulty. The solution of the second difficulty, however, does not imply that the first difficulty has been solved. Even if it can be shown that it is possible to establish an opposition of arguments for and against a particular definition, this might still not cover the specific way in which Sextus actually argues in $M$ III. Since resolving the second difficulty is a necessary, but not a sufficient condition of resolving the first one, the second difficulty is to be considered separately from the first difficulty. Although the second difficulty is more radical, though, it is easier to resolve than the first one, as we shall see shortly.

\section{Philosophical Strategies to Resolve the Two Difficulties}

In the remainder of this paper, I explore nine strategies to overcome the two difficulties. Firstly, I present one attempt to deny their first (common) premise, before, secondly, setting out three attempts to undermine these difficulties. Finally, I discuss five attempts to deny the second premise of the second difficulty. (Denying the second premise of the first difficulty is not an option, as it is a matter of fact that Sextus does not appeal to any arguments or considerations in favour of the particular definitions he attacks in $M$ III.) This survey of strategies to resolve the two difficulties for interpreting Sextus' attacks on particular geometrical definitions in $M$ III is not exhaustive; rather, my aim is to highlight those strategies that appear particularly obvious or promising. Most of these strategies solve the second difficulty without also solving the first one, whereas some of these strategies turn out not to be successful at all. Only one of the strategies that I shall survey appears to allow for a solution of both difficulties at once.

\subsection{Does the Sceptical Mode of Inquiry Require Arguments at all?}

The first (common) premise of the two difficulties states that suspension of belief regarding a geometrical definition requires arguments or considerations for and against that definition. Sceptical oppositions of dogmatic logoi "accounts, arguments, considerations" are not necessarily arguments; rather, any consideration in favour of each of the opposed claims will suffice to bring 
about a suspension of belief in the Sceptic. This view is also emphasized by Annas \& Barnes (2000, 51, n. 205): "The word $\lambda$ óros sometimes means 'argument': by alluding to the Stoic definition of an argument (see II 135), Sextus indicates that here he is taking the word logos in a more general sense-for any consideration in favour of a dogmatic claim you can find an equally convincing consideration in favour of something conflicting with it." Indeed, Sextus states that the Sceptic's opposition can equally occur between conflicting arguments and appearances, as well as between conflicting appearances alone ( $P H$ I.9, see Section 3.1 above). Also, Sextus often speaks of enargeia "clearness, obviousness" to indicate that a given claim can be supported by the fact that it is obviously true (for instance, $P H$ II.244; III.66; III.120). Consequently, the two difficulties seem to be resolved if we find some non-argumentative consideration in favour of the definition of a straight line as GHEITEMK that is as convincing as the negative counter-argument against that definition in M III.95-97.

However, this strategy ultimately fails in that it rests upon too narrow a notion of argument. Precisely what is the difference between an argument and a consideration in favour of a claim? Why should the obviousness of a given claim not count as an argument in support of that claim? I would like to propose that any kind of consideration in favour of a claim is some kind of argument, no matter what kind of argument, and no matter whether its premises are true or false. The word "argument" need not refer to a full-fledged proof or to a deductively valid argument; it simply refers to any evidence stated in support of the conclusion.

Moreover, even if there were 'non-argumentative' considerations in favour of a given claim, the problem would remain the same, given that ancient Geometers do not even state any non-argumentative considerations in favour of the particular geometrical definitions they lay down. The mere fact that a Geometer puts forward a definition does not by itself count as a consideration in favour of that definition. ${ }^{31}$ One might at best take the deductive use of a particular definition in a geometrical proof to be a consideration in favour of that definition. ${ }^{32}$

31 For the unpromising strategy of taking definitions as their own justifications, see Section 6.3.1 below.

32 For the promising strategy of taking the explanatory power of scientific definitions as evidence in their favour, see Section 6.3.5 below. 


\subsection{Three Strategies To Undermine the Difficulties}

Let me procced by discussing three strategies to undermine the two difficulties. Firstly, perhaps Sextus is not even concerned with definitions in $M$ III, but instead with mere descriptions? Indeed, Sextus does not speak of the "definition" of a straight line in M III.96, but of its hupographē "delineation". While horos and horismos ("definition") refer to the method of definition by stating the essence, hupographe is used in late antiquity to refer to the method of delineation, typically by stating a coextensive property or an inseparable accident. ${ }^{33}$ However, since Sextus expressly speaks of "definitions" in other passages of $M$ III - the Geometers "define" (horizein) a straight line (III.98) and the circle (III.107) - it is clear that Sextus targets definitions. ${ }^{34}$ Further metamathematical terminology in $M$ III suggests that he addresses scientific definitions. For instance, Sextus calls the definition of a straight line as GHEITEMK "an underlying principle" (III.94). ${ }^{35}$ Sextus says that "if [the principles of geometry] are done away with, no other geometrical theory can be assembled either" (III.92, see Section 3.2 above). He also speaks of "the theorems which come after their principles" (III.108), "principles" meaning definitions. Therefore, this strategy does not resolve the two difficulties.

The other two strategies suggest that Sextus need not be concerned with particular definitions because he suspends belief regarding definitions and scientific principles in general: firstly, regarding the effectiveness of the method of definition and division (see $P H$ II.16; 20; 205-212), and, secondly, regarding the Geometers' practice of proving theorems from unproved principles (by the Mode from Hypothesis introduced in $P H$ I.168; see $M$ III.7-17 and $M$ VIII.367-378). On this view, the argument against the definition of a straight line as GHEITEMK in M III.95-97 is nothing but an instance of a more general

33 Cf. Barnes 2003, 57-62.

34 Sextus' use of "delineation" in M III.96 is a pun: hupographein "to delineate" contains graphein, the corresponding nouns of which are gramme "line" and graphē "representation by means of lines, drawing". Cf. Bett 2018, 177, n. 6o. Sextus makes a related pun on grammikōs "by means of lines, by a diagram, by a proof" in $M$ III.92 (see Section 3.2 above).

35 The word Sextus uses here for "underlying" is a form of hupobainein "to stand under". Bury $(1949,291)$ takes "pros tas hupobebēkuias autōn archas" in M III.94 to mean "against their underlying principles", whereas Bett $(2018,177)$ translates this phrase as "against their lower-level principles". Bett thereby shifts the focus from the characterization of scientific principles as being explanatorily more fundamental than scientific theorems to the subdivision of scientific principles into fundamental (higher-level) and derivative (lower-level) principles. While I take Sextus in III.94 to appeal to the distinction between principles and theorems, rather than to that between fundamental and derivative principles, I shall return to the latter distinction in Section 6.3.5 below. 
suspension of belief. However, in $M$ III, Sextus does not present arguments against the methods of definition or principles-based proof in general, but only against particular definitions. Therefore, the latter two strategies do not resolve the first difficulty either. Yet, they might resolve the second difficulty if the Sceptic suspends belief regarding particular definitions by generally suspending belief regarding definition or principles-based proof.

\subsection{Five Strategies to Supply Arguments in Support of a Particular Geometrical Definition}

Let me now discuss five strategies to argue in favour of a particular geometrical definition. While the first of these suggests that a definition is self-evident and thus its own justification, the second strategy appeals to circular proof, the third to alternative definitions, the fourth to a dialectical establishing, and the fifth, finally, to a metamathematical justification of a particular geometrical definition.

\subsubsection{Self-evidence of a Definition}

One might argue that definitions are their own justification because definitions are self-evident: if the definition of a straight line as GHEITEMK serves as its own justification, then the Sceptic does not need to state any consideration in favour of that definition if he states that definition. The definition of a straight line as GHEITEMK indeed expresses the intuitive idea that a line is placed equally, on the same level, with its parts. Since the essence of a straight line seems to be something given in appearance, this definition might be taken to be intuitively evident by itself.

However, this strategy fails by virtue of the fact that the definition of a straight line as GHEITEMK is supposed to be a dogmatic belief. Dogmatic beliefs are-by Sextus' own definition of "dogmatic" (PH I.13, see Section 3.1 above)-something non-evident, not given in appearance. The mere fact that Sextus makes the effort of sceptically attacking particular geometrical definitions in $M$ III indicates that Sextus takes each of these definitions to be a dogmatic belief, and therefore something non-evident, not given in appearance. Therefore, this strategy neither resolves the second nor the first difficulty.

6.3.2 Circular Proof of a Definition

Aristotle occasionally refers to attempts to demonstrate a definition by way of a circular proof, presumably put forward by Xenocrates and Menaechmus. ${ }^{36}$

$36 \quad$ Posterior Analytics I.3; I.19-22; II.4, 91a35-b11; Prior Analytics II.5; cf. De Anima II.2, 413a112o. Cf. Barnes 1976. 
Perhaps, then, Sextus too appeals to such attempts to prove a definition? Circular proof of proposition $p$ occurs when $p$ is proved through another proposition $q$, whereas $q$ is proved through $p$. Circular proof, then, amounts to a proof of $p$ through $p$ itself. Thus, if the given definition of a straight line as GHEITEMK were to be proved by circular proof, then it would ultimately be proved through itself.

A circular proof of a definition would typically be countered by the Mode from Reciprocity (introduced in $P H$ I.169). Sextus indeed applies this Mode in $M$ III, but only to attack circular definitions, not circular proofs of definitions. ${ }^{37}$ Still, one can imagine a circular proof in which two different definitions explain one another, in which case both difficulties would be resolved.

However, a circular proof of a particular definition amounts to using that definition as its own justification, whereas the Sceptic is unable to appeal to a definition as its own justification (see Section 6.3.1 above). Therefore, circular proof cannot resolve the two difficulties either.

\subsubsection{Alternative Definitions and the Tenth Mode}

Although Sextus does not make use of his Ten Modes in $M$ III, the Tenth Mode from Customs and Persuasions (introduced in $P H$ I.145-163) suggests itself in this context. While geometrical definitions are the Geometers' respective persuasions and dogmatic beliefs, the Tenth Mode sets up oppositions among persuasions or customs or laws or dogmatic suppositions. ${ }^{38}$ Oppositions of arguments can be constructed by appealing to alternative definitions put forward by different Geometers, provided these alternative definitions are incompatible with each other. For instance, Sextus not only quotes the putative definition of a straight line as "the line which is placed equally with its parts" (grammē hè ex isou tois heautēs meresi keimenē = GHEITEMK, $M$ III.94; 96) but also as "that [line] which rotates equally with its limits" (hêtis ex isou tois heautēs perasi strephetai, III.98, henceforth "GHEITEPS"). Sextus thus introduces at least two alternative definitions of a straight line. (Still, these particular two definitions exclude one another only if one also assumes that the same definiendum cannot have different definitions.) The Tenth Mode can thus help the Sceptic to set up the following opposition of arguments (henceforth $\mathrm{R}_{4}$ ):

37 On Sextus' application of the Mode from Reciprocity against circular definitions in $M$ III.97 and III.99, see Section 2.2 above.

38 On the structure of the Tenth Mode, cf. Annas \& Barnes 1985, 16 o. 
(Positive argument)

(1) According to Geometer $A$, a straight line is defined as GHEITEMK.

(2) Therefore, a straight line is defined as GHEITEMK.
(Negative counter-argument) (1) According to Geometer $B$, a straight line is defined as GHEITEPS.
(2) Therefore, a straight line is defined as GHEITEPS.

(3) A straight line cannot be defined as both GHEITEPS and GHEITEMK.

(4) Therefore, a straight line is not defined as GHEITEMK.

(Suspension of belief)

We can neither affirm nor deny whether a straight line is, or is not, defined as GHEITEMK.

$\mathrm{R} 4$ shows that alternative definitions of the same definiendum can induce a suspension of belief regarding a particular geometrical definition. Hence, it is possible to apply Pyrrhonian scepticism to particular scientific definitions. However, while Sextus indeed quotes alternative definitions of a straight line in $M$ III, he never appeals to the Tenth Mode in $M$ III, or anywhere else in $M$ I-VI. Therefore, the Tenth Mode resolves the second, but not the first difficulty.

\subsubsection{Dialectical Establishing of a Definition}

One might plausibly suspect Sextus of implicitly appealing to dialectical arguments as positive considerations in favour of the particular geometrical definitions he attacks throughout $M$ III. Pyrrhonian scepticism and Aristotelian dialectic are similar in many respects, ${ }^{39}$ and both focus on attacking scientific principles, especially definitions, rather than scientific theorems. Particular dialectical arguments to which Sextus could appeal to support the definition of a straight line are not found in extant sources; ${ }^{40}$ but one could simply imagine there to be such an argument.

39 For a comparison of Pyrrhonian scepticism with Aristotelian dialectic, see Morison 2018, 317-319. Aristotle's account of dialectic is found in his Topics and Sophistical Refutations.

40 The only extant dialectical argument directed towards a definition of a straight line is found in Aristotle's Topics. In Topics VI.11, 148b24-32, Aristotle attacks the respondent's (i.e., Plato's) proffered definition of a straight line on the basis of the respondent's own views about complex propositions. However, while this argument is only destructive, Aristotle offers no positive argument to establish the proffered definition of a straight 
Yet, the sceptical and the dialectical modes of inquiry in fact seem to exclude one another. If the Sceptic wishes to employ a dialectical argument in support of the Dogmatist's proffered definition, then his objective-as a provisional Dialectician - is to dialectically refute the Dogmatist; this is achieved if something that is inconsistent with that putative definition is derived from the opponent's concessions. ${ }^{41}$ Thus, the Sceptic can dialectically establish the positive proposition 'A straight line is defined as GHEITEMK' only if the Dogmatist already defends something that is inconsistent with that proposition, such as the negative proposition 'A straight line is not defined as GHEITEMK'. Consequently, the Sceptic cannot dialectically establish the positive proposition 'A straight line is defined as GHEITEMK' if the Dogmatist defends 'A straight line is defined as GHEITEMK'. In this case, the Sceptic can only construct a dialectical argument to establish a conflicting claim such as 'A straight line is not defined as GHEITEMK'. Since the counter-argument against the definition of a straight line as GHEITEMK, which Sextus presents in $M$ III.95-97, proceeds from the positive proposition 'A straight line is defined as GHEITEMK', the Sceptic cannot appeal to a dialectical argument in support of the putative definition of a straight line as GHEITEMK.

The Sceptic is generally unable to employ dialectical arguments if one side of the opposition of dogmatic accounts is already given. This is the case in $M$ III.95-97, and in $M$ III in general, where the counter-arguments against particular definitions are not dialectically established, but borrowed from Epicurean critics of geometry (see Section 3.3 above). If, however, the Sceptic manages to dialectically establish both sides of that opposition, then he can make use of dialectic. While it generally seems possible for the Sceptic to dialectically establish opposing arguments for and against a definition, Sextus' arguments against particular definitions in $M$ III do not admit of a dialectical support. Therefore, dialectic resolves the second, but not the first difficulty.

\subsubsection{Metamathematical Justification of a Definition}

The most promising way of finding argumentative support for the given definition of a straight line as GHEITEMK is a 'metamathematical' appeal to the explanatory power and deductive success of that definition. If the proffered definition serves its purpose in subsequent proof, then this yields a good argument in its favour. Indeed, ancient Greek Geometers employ geometrical

line. Like Sextus' M I-VI, book VI of Aristotle's Topics is a series of dialectical arguments against proffered scientific definitions from various disciplines, whereby no argument in support of a particular definition is offered.

41 For Aristotle's requirement that the premises of dialectical arguments be the opponent's beliefs and concessions alone, see Sophistical Refutations 2, 165b3-5; cf. Plato's definition of refutation in Sophist 23ob7-10. 
definitions as deductive starting-points so as to unpack them into geometrical theorems.

While the explanatory power of a proffered definition yields evidence in support of that definition, its failure to explain certain theorems can serve as evidence against that definition. This line of argument is adopted by the Epicurean philosopher Zeno of Citium. In his commentary on the first book of Euclid's Elements (= in Eucl.), Proclus reports that Zeno attacks Euclid's definition of a straight line (El. I, def. 4), not by arguing that it is false, but that it fails to explain certain geometrical theorems. ${ }^{42}$ While the Sceptic can appeal to Zeno's criticism as a dogmatic counter-argument against $E l$. I, def. 4, the Sceptic's need to possess an argument in support of that definition would be satisfied if he found an instance where $E l$. I, def. 4 is deductively appealed to in geometrical proof.

This strategy accounts for sceptical attacks on definitions that are indeed employed as premises of geometrical proofs. For instance, Euclid's definitions of the circle (El. I. def. 15) and of a plane angle (El. I. def. 8) are deductively used as explanatory premises in subsequent proof. ${ }^{43}$ However, $E l$. I, def. 4 is not used in any geometrical proof, in which case the Sceptic can hardly rely upon its explanatory power. ${ }^{44}$

Still, there is one single occurrence in extant mathematical sources of a deductive appeal to a putative definition of a straight line, namely in (pseudo-?) Euclid's optical treatise Catoptrics: ${ }^{45}$

Each of the [objects] seen in plane mirrors is seen along the perpendicular [dropped] from the [object] seen. Let CD be a plane mirror, and B the eye, and A the [object] seen, and let AC be the perpendicular [dropped] from the [object] seen to the mirror. Therefore, since it is assumed in the appearances that $\mathrm{A}$ is not seen to occupy place $\mathrm{C}$, $\mathrm{A}$ will therefore be seen with the straight [line] AC. But it is also seen with the straight [line] BD.

42 In Eucl. 199,3-200, 3; 214,15-22 (translation in Morrow 1992, 156; 168); cf. Apelt 1891, 257; Mueller 1982, 92 .

43 El. I. def. 15 is deductively appealed to in $E l$. I.1-3, 12, 22, II.14, III.2, 5-6, 17, 20, 25, 33, 37, IV.1, 4, 6, 15; and $E l$. I. def. 8 in El. III.1-2. Note that Sextus attacks variants of Euclid's definitions of the circle in $M$ III.107 and of the angle in III.10o-106 (see section 2.1 above).

44 Commentators commonly claim that $E l$. I. def. 4 is in fact mathematically useless: see, e.g., Apelt 1891, 257; Heath 1921, i, 384; Fletcher 1938, 64; Mueller 1981, 39-40; 1982, 73; Gray 1989, 28; Netz 1999, 95; Mendell 2007, 34.

45 Also, Aristotle (Physics II.9, 200ar6-19) suggests that the proof of theorem that the angles of a triangle equal two right angles requires the definition of a straight line; yet Aristotle does not state any definition of a straight line. Moreover, about three centuries after Sextus, Proclus appeals to El. I, def. 4 to prove that two straight lines cannot have a common segment: see in Eucl. 215,14-23. 
Therefore, [it is] also [seen] along E. For, we have assumed that straight

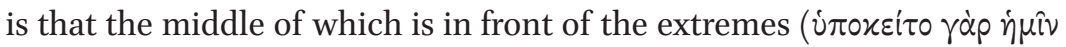

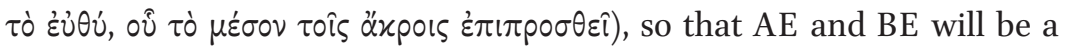
straight [line].

Catoptrics 16, 312, 9-19

In this quasi-geometrical proof, a definition of a straight line is used to explain why everything seen in mirrors is seen along the perpendicular straight line dropped from the object of vision. Since that definition is supposed to serve as a deductive premise in a scientific proof (regardless of its actual scientific value), it can be taken to have an explanatory function. If explanatory power is a requirement for being a definition, and if that definition satisfies all further requirements for it to be a definition, then one has good reasons to believe that it really is a definition.

Accordingly, since the definition of a straight line in Catoptrics 16 is a variant of the putative definition of a straight line as GHEITEMK, which Sextus attacks in $M$ III.95-97, the Sceptic finds support for the view that the putative definition of a straight line as GHEITEMK is a definition. The corresponding sceptical argument can be sketched along the following lines (henceforth $\mathrm{R}_{5}$ ):

(Positive argument)

(1) The Catoptrics' definition of a straight line satisfies all requirements for being a definition, including explanatory power. ${ }^{46}$

(2) Therefore, the Catoptrics' definition of a straight line is a definition.

(3) The putative definition of a straight line as GHEITEMK is a variant of the Catoptrics' definition of a straight line.

(4) Therefore, the putative definition of a straight line as GHEITEMK is a definition, too.
(Negative counter-argument) [see $\mathrm{R} 1$ above]

Therefore, a straight line is not defined as GHEITEMK.

\footnotetext{
(5) Therefore, a straight line is defined as GHEITEMK.
}

46 This premise needs to be added, as explanatory power alone is not sufficient to provide a metamathematical justification for proposition $p$ to be a definition, as propositions other than definitions can have explanatory power. 
(Suspension of belief)

We can neither affirm nor deny whether a straight line is, or is not, defined as GHEITEMK.

The negative dogmatic argument against the definition of a straight line as GHEITEMK in M III.95-97 is here confronted with a 'metamathematical' dogmatic argument in support of that definition. These two opposing arguments might strike the Sceptic as equally convincing, and bring about a suspension of belief on the matter of whether or not a straight line is defined as GHEITEMK. Metamathematical justification of a geometrical definition thus resolves the second difficulty. Since it is possible that Sextus appeals to precisely this kind of argument in his various attacks on particular geometrical definitions in $M$ III, this strategy resolves the first difficulty as well. This is especially suggested by Sextus' metamathematical jargon to describe his opponents' use of geometrical definitions as starting-points to prove theorems (see Section 6.2 above). Consequently, $\mathrm{R}_{5}$ is the only successful strategy among those hitherto surveyed.

However, there seems to remain a serious obstacle to this strategy. Metamathematical justification can indeed account for definitions of derivative geometrical items such as a straight line, the circle, and the angle, given that their respective definitions are appealed to in scientific proof. But this strategy cannot equally account for definitions of fundamental geometrical items such as the point, the line, the surface, and the solid, given that their respective definitions are never appealed to as deductive premises in geometrical proof. Yet, the Sceptic also, and especially, desires to suspend belief regarding definitions of fundamental geometrical items.

While the Sceptic indeed cannot avail himself of any geometrical proofs, there are still non-geometrical proofs in which definitions of fundamental geometrical items are appealed to as deductive premises. For instance, preEuclidean variants of Euclid's definition of the point (El. I. def. 1) are used in Aristotle's philosophical arguments against geometrical atomism, ${ }^{47}$ against the substantiality of geometrical limits, ${ }^{48}$ and against the view that the soul is a magnitude. ${ }^{49}$ Aristotle also uses a pre-Euclidean variant of Euclid's definition of the solid (El. I. def. 1-2) to prove that an infinite body cannot exist. ${ }^{50}$ Therefore, metamathematical justification resolves the first difficulty also with regard to definitions of fundamental items.

\footnotetext{
47 Physics VI.1, 231a18-28; 29-b6; De Caelo III.1, 299a2-b14; Metaphysics M.2, 1076b5-8.

48 Metaphysics B.5, 1002a29-b4; cf. K.2, 106ob19-22.

49 De Anima. I.3, 407a3-21.

50 Metaphysics K.10, 1066b22-34.
} 
When the sceptical mode of inquiry is directed towards particular geometrical definitions, it requires there to be arguments, or considerations, in favour of such definitions, whereas the geometrical mode of inquiry excludes arguments or considerations in favour of such definitions. Despite this discrepancy, the absence of arguments or considerations in favour of particular geometrical definitions is strikingly common to both Sextus' $M$ III and ancient Greek geometry. The absence of arguments in support of particular geometrical definitions in $M$ III seems to suggest that Sextus' arguments in $M$ II against such definitions are not instances of Pyrrhonian scepticism, but rather of negative dogmatism. This first, well-known difficulty for interpreting $M$ III can be overcome by supplying the missing arguments in support of particular definitions. This potential solution, however, is complicated by the fact that ancient Geometers do not argue in support of any of their definitions. If the Sceptic is not provided with any argument or consideration in favour of a particular geometrical definition, then he cannot establish an opposition of arguments and is thus unable to suspend belief regarding that particular definition. This is the second, heretofore unnoticed difficulty for interpreting $M$ III. Nonetheless, various ways can be found for the Sceptic to deploy evidence in favour of a putative scientific definition. While the Sceptic cannot appeal to any geometrical arguments, he can instead mobilise non-geometrical, 'philosophical' considerations in favour of such definitions to argue for and against a geometrical definition. For instance, the Sceptic can appeal to alternative definitions of the same item, to dialectical reasoning, and to metamathematical justifications, as we saw. This resolves the second difficulty, so that it turns out to be possible for the Sceptic to suspend belief regarding a particular geometrical definition. As pertains to the first difficulty, the fact that ancient geometry states its definitions without any proof or justification of some other sort might be the reason why Sextus does not mention any considerations in favour of particular geometrical definitions in $M$ III. While metamathematical justification of a particular definition appears to be the most promising strategy to fill the gaps in Sextus' text, it still remains uncertain precisely which arguments or what kinds of argument in support of particular geometrical definitions Sextus has in mind in $M$ III. This problem is not peculiar to $M$ III, but pervades all sceptical attacks on particular scientific definitions in M I-VI, as well as in Sextus' other works. 


\section{Acknowledgements}

This work has been supported by the German Research Foundation (DFG) under the grant number GRK 1939. Earlier versions of this paper were presented to responsive audiences in Berlin (Humboldt-Universität), Brussels (Vrije Universiteit), Cambridge (St. John's College), Cologne (Universität Köln), Durham (Durham University), Hamburg (Maimonides Centre for Advanced Studies-Jewish Scepticism), Jerusalem (Van Leer Jerusalem Institute), London (University College London; King's College London), and Paris (École Normale Supérieure / Université Paris-Diderot). I wish to thank here Arif Ahmed, Vincenzo Corti, Gideon Freudenthal, Zev Harvey, Juliette Kennedy, Diego Machuca, Jan Opsomer, David Rabouin, Tobias Rosefeldt, Stephan Schmid, Johanna Schmitt, Charles Snyder, Tue Søvsø, Emidio Spinelli, Gisela Striker, Guiseppe Veltri, Máté Veres, Justin Vlasits, and all the others who have contributed to the discussion of my views on those occasions. I especially thank Fabio Acerbi, Tim Button, Benjamin Morison, and the anonymous reviewers of this article for their extremely helpful comments upon the content and form of earlier drafts. I am also indebted to Jens Kristian Larsen and Philipp Steinkrüger for their meticulous editorial efforts. For proof-reading, I would like to thank Nicholas Robin Courtman.

\section{Bibliography}

\section{Primary Texts}

[Euclid.] Euclidis Opera Omnia. Vols. I-IX. Heiberg, J.L. \& Menge, H. (eds.), 1883-1916. Leipzig: Teubner. $(=E l$.)

[Hero of Alexandria.] Heronis Alexandrini Opera Quae Supersunt Omnia. Vol. Iv: Heronis Definitiones Cum Variis Collectionibus. Heronis Quae Feruntur Geometrica. Heiberg, J.L. (ed.), 1912. Leipzig: Teubner. (= Deff.)

[Proclus.] Procli Diadochi in primum Euclidis Elementorum librum commentarii. Friedlein, G. (ed.), 1873. Leipzig: Teubner. (= in Eucl.)

Proclus. A Commentary on the First Book of Euclid's Elements. Morrow, G.R. (tr.), 1992. Princeton: Princeton University Press.

[Sextus Empiricus.] Sexti Empirici Opera, Vol. 1: ПYPP $\Omega N E I \Omega N ~ Y \Pi O T Y \Pi \Omega \Sigma E \Omega N$. Mutschmann, H. (ed.), 1912. Leipzig: Teubner. $(=P H)$

[Sextus Empiricus.] Sexti Empirici Opera, Vol. 2: Adversus Dogmaticos libros quinque (Adv. Mathem. VII-XI) continens. Mutschmann, H. (ed.), 1914. Leipzig: Teubner. $(=M \mathrm{VII}-\mathrm{XI})$ 
[Sextus Empiricus.] Sexti Empirici Opera, Vol. 3: Adversus Mathematicos libros I-VI continens. Mutschmann, H. \& Mau, J. (eds.), 1954. Leipzig: Teubner, 1954. (= M I-VI)

Sextus Empiricus. Bekker, I. (ed.) 1842. Berlin: Reimer.

Sextus Empiricus. Outlines of Scepticism. Annas, J. \& Barnes, J. (trs.), 200o. Cambridge: Cambridge University Press.

Sextus Empiricus. Against the Professors. Bury, G. (tr.), 1949. Cambridge, MA: Harvard University Press.

\section{Secondary Literature}

Annas, J. \& Barnes, J. 1985. The Modes of Scepticism: Ancient Texts and Modern Interpretations. Cambridge: Cambridge University Press.

Apelt, O. 1891. Die Widersacher der Mathematik im Altertum. In: Apelt, O., Beiträge zur Geschichte der Philosophie. Leipzig: Teubner, 253-270.

Barnes, J. 1976. Aristotle, Menaechmus, and Circular Proof. Classical Quarterly (New Series) 26(2), 278-292.

Barnes, J. 1988. Scepticism and the Arts. Apeiron 21(2), 53-77.

Barnes, J. 1997. The Beliefs of a Pyrrhonist. In: Burnyeat, M.F. \& Frede, M. (eds.), The Original Sceptics: A Controversy. Indianapolis —Cambridge: Hackett, 58-91.

Barnes, J. 2003. Porphyry. Introduction. Oxford: Oxford University Press.

Bett, R. 2019. How to be a Pyrrhonist. The Practice and Significance of Pyrrhonian Scepticism. Cambridge: Cambridge University Press.

Blank, D.L. 1998. Sextus Empiricus: Against the Grammarians. Oxford: Oxford University Press.

Burnyeat, M.F. 1980. Can the Sceptic Live His Scepticism? In: Schofield, M., Burnyeat, M.F. \& Barnes, J. (eds.), Doubt and Dogmatism. Studies in Hellenistic Philosophy. Oxford: Clarendon Press, 20-53.

Cambiano, G. 2008. Philosophy, science and medicine. In: Keimpe, A., Barnes, J., Mansfeld, J. \& Schofield, M. (eds.), The Cambridge History of Hellenistic Philosophy. Cambridge: Cambridge University Press, 585-613.

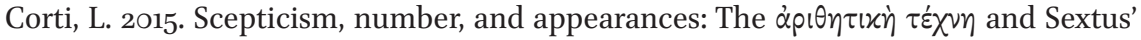
targets in M I-VI. Philosophie Antique 15, 121-145.

Decleva Caizzi, F. 1992. Sesto e gli scettici. Elenchos 13, 279-327.

Delattre, J. 1994. Géométrie et géomètres antiques. In: Delattre, J. (ed.), Géométrie ou géométries antiques? Lille: Presses de l'Université de Charles-de-Gaulle-Lille 3, 87-109.

Desbordes, F. 199o. Le scepticisme et les 'Arts Liberaux': une étude de Sextus Empiricus, adversus Mathematicos I-VI. In: Voelke, A.-J. (ed.), Le scepticisme antique. Perspectives historiques et systématiques. Geneva, Lausanne, Neuchâtel: Cahiers de la Revue de Théologie et de Philosophie, 167-179.

Dumont, J.-P. 1972. Le scepticisme et le phenomène, Paris: Librairie Philosophique J.Vrin. 
Dye, G. \& Vitrac, B. 2009. Le Contre les géomètres de Sextus Empiricus: sources, cible, structure. Phronesis 54(2), 155-203.

Eves, H. 1958. An Introduction to the Foundations and Fundamental Concepts of Mathematics. New York: Holt, Rinehart and Winston.

Fletcher, W.C. 1938. Euclid. The Mathematical Gazette 22(248), 58-65.

Frede, M. 1997. The Sceptic's Beliefs. In: Burnyeat, M.F. \& Frede, M. (eds.), The Original Sceptics: A Controversy. Indianapolis, Cambridge: Hackett, 1-24.

Freytag, W. 1995. Mathematische Grundbegriffe bei Sextus Empiricus. Hildesheim: Olms. Golos, E.B. 1968. Foundations of Euclidean and Non-Euclidean Geometry. New York et. al.: Holt, Rinehart, and Winston, Inc.

Gray, J. 1989. Ideas of Space. Euclidean, Non-Euclidean, and Relativistic. Oxford: Clarendon Press.

Hankinson, R.J. 1995. The Sceptics, London: Routledge.

Heath, T.L. 1921. A History of Greek Mathematics. 2 vols. Oxford: Clarendon Press.

Heath, T.L. 1956. Euclid. The Thirteen Books of the Elements. 3 vols. Cambridge-New York: Dover.

Janáček, K. 1972. Sextus Empiricus'sceptical methods. Prague: University Karlova Praha. Janáček, K. 1994. M I-VI als Schlüssel zu Sextos Empeirikos' Schriften. Folia philologica 117(3/4), 71-178. Reprinted in: Erler, M., Gall, D., Heitsch, E., Koenen, L. \& Zintzen, C. (eds.), Karel Janáček. Studien zu Sextus Empiricus, Diogenes Laertius und zur pyrrhonischen Skepsis. Berlin, New York: De Gruyter, 349-357.

Machuca, D. 2006. The Pyrrhonist's Ataraxia and Philanthropia. Ancient Philosophy 26, 111-139.

Mendell, H. 2007. Two Traces of Two-Step Eudoxan Proportion Theory in Aristotle: a Tale of Definitions in Aristotle, with a Moral. Archive for the History of Exact Sciences $61,3-37$.

Morison, B. 2011. The Logical Structure of the Sceptic's Opposition. Oxford Studies in Ancient Philosophy 40, 265-295.

Morison, B. 2018. The Sceptic's Modes of Argumentation. In: Bénatouïl, T. \& Ierodiakonou, K. (eds.), Dialectic after Plato and Aristotle. Cambridge: Cambridge University Press, 283-319.

Morison, B. 2019. Sextus Empiricus. In: Zalta, E.N. (ed.), The Stanford Encyclopedia of Philosophy (Fall 2019 Edition). URL: <https://plato.stanford.edu/entries/sextusempiricus/>. Accessed: November 21, 2019.

Mueller, I. 1981. Philosophy of Mathematics and Deductive Structure in Euclid's Elements. Cambridge, London: MIT Press.

Mueller, I. 1982. Geometry and scepticism, In: Barnes, J., Brunschwig, J., Burnyeat, M. \& Schofield, M. (eds.), Science and Speculation. Studies in Hellenistic Theory and Practice, 69-95. Cambridge: Cambridge University Press. 
Netz, R. 1999. The Shaping of Deduction in Greek Mathematics. A Study in Cognitive History. Cambridge: Cambridge University Press.

Pappenheim, E. 1877. Des Sextus Empiricus Pyrrhoneische Grundzüge, Leipzig: L. Heimann-Verlag.

Pellegrin, P., Dalimier, C., Delattre, D., Delattre, J. \& Pérez, B. (eds.). 2002. Sextus Empiricus. Contre les professeurs, Paris: Éditions du Seuil.2018

Perin, C. 2010. The Demands of Reason: An Essay on Pyrrhonian Scepticism. Oxford: Oxford University Press.

Russo, A. 1972. Sesto Empirico, Contro Imatematici, Bari: Laterza.

Russo, L. 1998. The Definitions of Fundamental Geometric Entities Contained in Book I of Euclid's Elements. Archive for the History of the Exact Sciences 52, 195-219.

Spinelli, E. 2010. Pyrrhonism and the specialized sciences. In: Bett, R. (ed.), The Cambridge Companion to Ancient Scepticism. Cambridge: Cambridge University Press, 249-264.

Striker, G. 1983. The Ten Tropes of Anaesidemus. In: Burnyeat, M.F. (ed.), The Skeptical Tradition. Berkeley, Los Angeles, London: University of California Press, 95-115.

Zeller, E. 1881. Die Philosophie der Griechen in ihrer geschichtlichen Entwicklung. Dritter Theil, Zweite Abteilung: Die nacharistotelische Philosophie, Zweite Hälfte. 3rd edition. Leipzig: Fues's Verlag (R. Reisland). 